\title{
PENGARUH POLA PELATIH KOOPERATIF TERHADAP MOTIVASI BERPRESTASI ATLET BOLA BASKET PUTRI SMA 17 AGUSTUS 1945 SURABAYA
}

\author{
Eka Kurnia Darisman, Suharti \\ Pendidikan Kepelatihan Olahraga Universitas PGRI Adi Buana Surabaya \\ e-mail: ekakurniadarisman68@gmail.com
}

\begin{abstract}
In order to achieve the expected training objectives and achievements, trainers should be aware that the increased performance of their athletes is related to the personal development of the athlete himself. Some people disagree that the coaching style has the influence of the athlete's training process. The style of coaching can affect athletes toward achievement.

This study aims to determine whether there is influence of co-operative trainer pattern to the achievement motivation of female basketball athletes in 17 Agustus 1945 Senior High School Surabaya.

In this study using pre-experimental design. The population is the extracurricular participants of basketball in 17 Agustus 1945 Senior High School Surabaya. Using stratified sampling technique with 15 people as sample.

The 15 people are the core team of basketball team in 17 Agustus 1945 Senior High School Surabaya. The measurement test of each variable is by using a closed questionnaire that has been tested for its validity and reliability. While the value of $b$ indicates that the cooperative coach's pattern of achievement motivation will be able to help increase as much as 0.622. And from the results of this study shows that 50.98\% female basketball athletes in 17 Agustus 1945 Senior High School Surabaya achievement motivation influenced by the pattern of co-operative coach.

The results of this study indicate that achievement motivation and cooperative pattern are in linear graphics. A strong and significant positive relationship of 0.714. 0.714>0.433 Ha is accepted, it indicates that there is a relationship between co-operative coach pattern toward achievement motivation.
\end{abstract}

Keywords: Coach, cooperative style, achievement motivation

\begin{abstract}
ABSTRAK
Agar dapat tercapainya tujuan pelatihan dan prestasi yang diharapkan, maka pelatih harus menyadari bahwa meningkatnya prestasi atlet mereka berhubungan dengan perkembangan diri pribadi atlet itu sendiri. Beberapa orang kurang sependapat bahwa gaya pembinaan mempunyai pengaruh proses pelatihan atlet. Gaya pembinaan dapat mempengaruhi atlet menuju prestasi.

Penelitian ini bertujuan untuk mengetahui apakah ada pengaruh pola pelatih kooperatif terhadap motivasi berprestasi atlet bola basket putri di SMA 17 Agustus 1945 Surabaya.

Pada penelitian ini menggunakan desain pre-eksperimental. Populasinya adalah peserta ekstrakurikuler bola basket SMA 17 Agustus 1945 Surabaya. Menggunakan teknik stratified sampling dengan 15 orang sebagai sampelnya. 15 orang tersebut adalah tim inti dari tim basket SMA 17 Agustus 1945 Surabaya. Tes pengukuran masing-masing variabel adalah dengan menggunakan kuesioner tertutup yang telah diuji validitas dan reliabilitasnya.
\end{abstract}


Hasil penelitian ini menunjukkan bahwa motivasi berprestasi dan pola kooperatif berada dalam grafis yang linear. Adanya hubungan positif yang kuat dan signifikan sebesar 0,714. 0,714 > 0,433 Ha diterima, hal ini menunjukkan bahwa ada hubungan antara pola pelatih koperatif terhadap motivasi berprestasi. Sementara nilai b menunjukkan bahwa pola pelatih koperatif terhadap motivasi berprestasi akan dapat membantu meningkatkan sebanyak 0,622. Dan dari hasil penelitian ini menunjukkan bahwa 50,98 \% atlet bola basket putri SMA 17 Agustus 1945 Surabaya motivasi berprestasinya dipengaruhi oleh pola pelatih kooperatif.

Kata Kunci: pelatih, pola kooperatif, motivasi berprestasi.

\section{PENDAHULUAN}

Sudah pasti tidak ada orang yang menyangkal, bahwa perkembangan merupakan hal yang berkelanjutan, akan tetapi untuk dapat lebih mudah memahaminya, biasanya orang akan menggambarkan perkembangan tersebut dalam fase-fase atau periode-periode tertentu. Oemar Hamalik (2010:84) menambahkan "Perkembangan menunjuk kepada perubahan yang progresif dalam organisme, tidak hanya segi fisik (jasmaniah), melainkan juga dalam segi fungsi, misalnya kekuatan dan koordinasi."

Menjadi sebuah keharusan bagi setiap pendidik yang bertanggung jawab bahwa dalam melaksanakan tugasnya harus berbuat dalam cara yang sesuai dengan kondisi anak didik. Karena itu pengetahuan psikologis mengenai anak didik dalam proses pendidikan adalah hal yang perlu dan penting bagi setiap pendidik. Jika kita berbicara dalam dunia olahraga, pendidik memiliki nama lain yang sering disebut dengan sebutan pelatih.

Sukadiyanto (2011:4) menjelaskan bahwa "Pelatih adalah seseorang yang memiliki kemampuan profesional untuk membantu mengungkapkan potensi olahragawan menjadi kemampuan yang nyata secara optimal dalam waktu yang relatif singkat". Untuk mencapai tujuan dari program latihan yang telah dibuat dan agar dapat menggapai prestasi kemenangan dalam pertandingan maka penting bagi para pelatih untuk menyadari dan memahami peningkatan prestasi atlet dan perkembangan pribadinya. 
Dalam olahraga prestasi, baik pelatih maupun atlet menginginkan reward atas kerja kerasnya dalam melatih dan berlatih. Oleh karena itu agar mendapatkan reward tersebut, mereka harus melewati proses yang tidak main-main. Untuk dapat bertahan menjalani proses tersebut, maka diperlukan kesabaran dan motivasi yang sangat tinggi.

Motivasi dalam bidang olahraga yang harus dimiliki oleh atlet adalah motivasi berprestasi. Dijelaskan oleh Gill, Weinberg dan Gould dalam Komarudin (2013:25) jika motivasi berprestasi akan berorientasi kepada seseorang yang berjuang menyelesaikan tugas, bertahan walau mengalami kegagalan, dan pengalaman membanggakan dalam sebuah prestasi. Motivasi berprestasi dapat tumbuh dari keinginan diri sendiri atau dorongan dari lingkungan sekitar.

Pelatih yang sukses dan berhasil tidak hanya memiliki kemampuan dan pengetahuan yang mumpuni, namun harus bisa memotivasi atlet-atletnya karena motivasi mempunyai peran penting dalam membantu menentukan berhasil tidaknya atlet dalam proses latihan dan pertandingan. Peran pelatih tidaklah sedikit, diperoleh dari Institut Olahraga Australia. (Dan Gardon, 2009:4) peran pelatih sangat krusial dalam bidang olahraga, peran pelatih dapat digambarkan sebagai berikut:

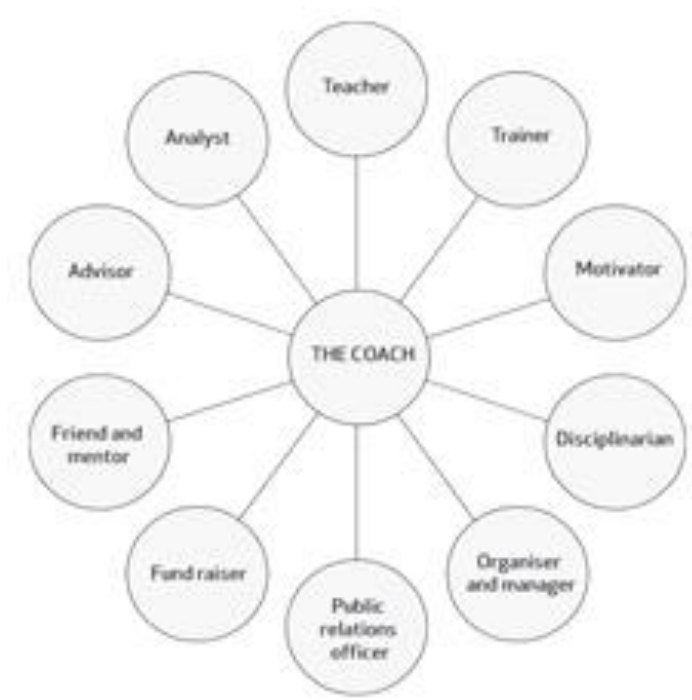

Gambar 1. Peran seorang Pelatih Diadaptasi dari Institut Olahraga Australia "Coaching Science", England: Learning Matters Ltd. (Dan Gardon, 2009:4)

Banyak yang tidak menyadari jika ciri khas atau pola melatih berpengaruh terhadap proses berlatih atlet. "Gaya atau pola ini akan menentukan bagaimana pelatih memilah keterampilan teknik dan taktik yang akan diajarkan" (Rainer Martens, 2004:30). 
Melalui gaya (style) sebagai sebuah kekhasan dari seseorang akan membantu pelatih untuk dapat merealisasikan program yang telah disusun. Dengan ciri khas inilah, pelatih memegang kendali atas atlet terhadap program yang telah disusun untuk direali-sasikan demi tujuan memperoleh prestasi tertinggi. Ketika pelatih telah mendapatkan respon atlet, maka akan mudah untuk para pelatih menyampaikan materi, manfaat, serta tujuan dari program tersebut. Rainer Martins (2004:30) membagi pola pelatih menjadi tiga jenis yakni pola otoriter, pola pengasuh, dan pola kooperatif. Sedangkan menurut Pate, McClenaghan dan Rotella (1984) membaginya menjadi empat jenis yaitu pola otoriter, pola demokratis, pola yang lebih memperhatikan atlet (People Centered), dan pola yang lebih menekankan pada tugas (Task-Oriented)".

Dari penjabaran di atas, peneliti melakukan penelitian tentang pengaruh pola pelatih terhadap motivasi berprestasi dalam keolahragaan. Peneliti akan meng- ambil salah satu pola yaitu pola kooperatif milik Rainer Martens terhadap motivasi berprestasi pada atlet bolabasket putri. Diharapkan penelitian ini dapat menjadi referensi ilmu pengetahuan di bidang psikologi perkembangan dibidang keolahragaan dan bahan pertimbangan untuk para pelatih guna membangun karakteristik diri (kekhasan) menjadi pelatih yang ideal untuk atletnya. Sehingga penelitian ini memiliki tujuan untuk mengetahui seberapa besar pengaruh dari pola pelatih kooperatif terhadap motivasi berprestasi pada atlet bola basket putri SMA 17 Agustus 1945 Surabaya.

\section{METODE PENELITIAN}

Berdasarkan sifat permasalahannya, maka penelitian ini adalah penelitian kausal-komparatif. Suharsimi Arikunto (2010:30) menjelaskan penelitian kausalkomparatif, bertujuan untuk mengetahui kemungkinan adanya hubungan sebabakibat berdasarkan pengamatan terhadap akibat yang ada, kemudian menduga faktor 
sebagai penyebab melalui pengumpulan data tertentu. Jenis rancangan penelitian eksperimen ini adalah pra-eksperimental (Pre-experimental) menggunakan one-shot model. Diambil populasi dari peserta ekstrakurikuler bola basket SMA 17 Agustus 1945 Surabaya. Pengambilan subjek penelitian menggunakan teknik milik Suharsimi Arikunto (2010:181) yaitu sampel berstrata atau stratified sample dengan sampel atlet bola basket putri SMA 17 Agustus 1945 Surabaya. Teknik pengumpulan data yang digunakan adalah kuesioner atau angket dengan skala bertingkat yang mengandung indikatorindikator tentang pola pelatih kooperatif dan tentang motivasi berprestasi. Pengumpulan data atau kuesioner ini bersifat tertutup karena sudah tersedia lima opsi jawaban sehingga memudahkan subjek dan menghemat waktu yang digunakan saat pengambilan data.

Peneliti menggunakan enam cara perhitungan dari data yang sudah diperoleh. Berikut penjabarannya.

\section{Uji validitas}

Validitas dalah suatu ukuran yang menunjukkan tingkat-tingkat kevalidan atau kesahihan suatu instrument (Suharsimi Arikunto, 2010:211). Sehingga untuk memperoleh kevalidan instrument, peneliti harus hati-hati sejak awal penyusunannya.

\section{Uji reliabilitas}

Suatu tes dikatakan memiliki taraf kepercayaan yang tinggi jika tes tersebut dapat member hasil yang tetap (Suharsimi Arikunto (2012:100). Reliabilitias adalah ukuran suatu kestabilan dan konsisten responden dalam menjawab hal yang berkaitan dengan pertanyaan dan disusun dalam bentuk kuesioner (V. Wiratna, 2015:192)

\section{Persamaan regresi}

Regresi sederhana didasarkan pada hubungan fungsional ataupun kausal satu variabel bebas dan satu variabel terikat (Sugiyono, 2005:243). 


\section{Koefisien Korelasi (rXY)}

Koefisien korelasi adalah suatu alat statistik yang dapat digunakan untuk membandingkan hasil pengukuran dua variabel yang berbeda agar dapat menentukan tingkat hubungan antara variabel-variabel ini (Suharsimi Arikunto,2010:313).

\section{Uji Signifikan (thitung)}

Uji signifikan bertujuan untuk menguji signifikasi hubungan untuk seluruh populasi. Jika terbukti signifikan, maka data tersebut dapat berlaku pada seluruh populasi di mana sampel tersebut berada.

\section{Koefisien Determinasi (Kd)}

Untuk mengetahui persentase korelasi variabel $\mathrm{X}$ dan variabel $\mathrm{Y}$, maka dilakukan uji determinasi dengan mengkuadratkan hasil koefisien korelasi.

Keenam teknik analisis data di atas akan menghasilkan nilai atau angka yang berguna untuk menentukan hasil akhir hipotesis yang peneliti ajukan. Jika $\mathrm{H}_{\mathrm{o}}$ diterima, maka hasil hipotesisnya adalah tidak ada pengaruh. Sebaliknya, jika $\mathrm{H}_{\mathrm{o}}$ ditolak dan $\mathrm{H}_{\mathrm{a}}$ diterima, maka hasil hipotesisnya adalah ada pengaruh antara kedua variabel yang sudah diajukan peneliti.

\section{HASIL PENELITIAN}

Data-data yang didapat adalah data berupa angka-angka karena penelitian ini menggunakan penelitian kuantitatif. Angka-angka yang dihasilkan kemudian akan diatur, diolah, disajikan, dan dianalisis menggunakan cara-cara yang runtut melalui uji validitas, uji reabilitas, mencari garis regresi melalui persamaan $\mathrm{X}$ dan $\mathrm{Y}$, koefisien korelasi, uji signifikan, dan koefisien determinasi.

\section{Uji Validitas}

Dikatakan variabel itu valid apabila $\mathrm{r}_{\text {tabel }}<\mathrm{r}_{\text {hitung }}$ dengan $\mathrm{r}_{\text {tabel }}$ di mana $\mathrm{df}=\mathrm{n}-2$ dan sig. sebesar 5\% (V. Wiratna, 2015:

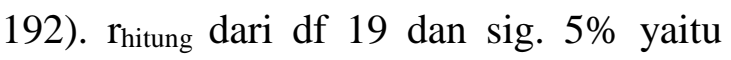
0.369 .

Variabel pola pelatih kooperatif menunjukkan $r_{\text {hitung }}$ antara 0.476-0.851, maka dinyatakan valid. Dan variabel motivasi berprestasi menghasilkan $\mathrm{r}_{\text {hitung }}$ berki- 
sar antara 0.389-0.833, maka dinyatakan valid.

\section{Uji Reliabilitas}

Data akan reliabel jika nilai Alpha $>0.60$. Berdasarkan perhitungan reliabilitas manual milik Suharsimi Arikunto (2010), maka variabel pola pelatih kooperatif menunjukkan nilai Alpha sebesar 0.8656 yang berarti reliabel. Dan motivasi berprestasi dengan nilai Alpha sebesar 0.8999 sehingga dinyatakan reliabel.

\section{Persamaan Regresi}

Hasil perhitungan regresi menghasilkan persamaan $\mathrm{Y}=24.997+0.622 \mathrm{X}$. Persamaan tersebut, dilanjutkan dengan membuat grafik sebagai garis regresi. Grafik ini digambarkan melalui garis $\mathrm{X}$ dan garis $\mathrm{Y}$ melalui perhitungan jika $\mathrm{X}$ diketahui, dan $\mathrm{Y}$ dihitung dengan perhitungan menggunakan persamaan $\mathrm{Y}=$ $24.997+0.622 X$.

Sehingga jika diinterpretasi ke

$$
\text { Garis Regresi }
$$

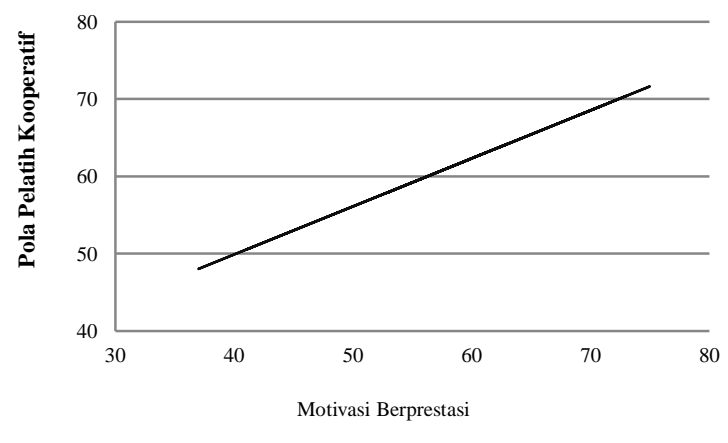

dalam grafik regresi akan menghasilkan garis linear. Seperti gambar berikut:

Keterangan: $\bar{x}=60$

$$
\overline{\mathrm{y}}=62
$$

\section{Koefisien Korelasi (r)}

Untuk mencari seberapa besar hubungan pola pelatih kooperatif dan motivasi berprestasi, hasil akhirnya berupa $\mathrm{r}_{\text {hitung }}$ sebesar 0.714 yang masuk ke dalam kategori kuat.

\section{Uji Signifikan (thitung)}

Untuk menguji signifikansi hubungan untuk seluruh populasi. Dikatakan data tersebut signifikan apabila $\mathbf{r}_{\text {hitung }}$ $>\mathrm{r}_{\text {tabel }}$ masuk ke daerah penolakaan $\mathrm{H}_{\mathrm{o}}$, maka data signifikan.

$\mathrm{r}_{\text {tabel }}$ dengan df sebesar $19(\mathrm{n}-2)$ dan sig. 5\% adalah 2.093 dan $r_{\text {hitung }}$ sebesar 4.445 sehingga masuk ke daerah penolakan $\mathrm{H}_{\mathrm{o}}$ seperti gambar berikut:

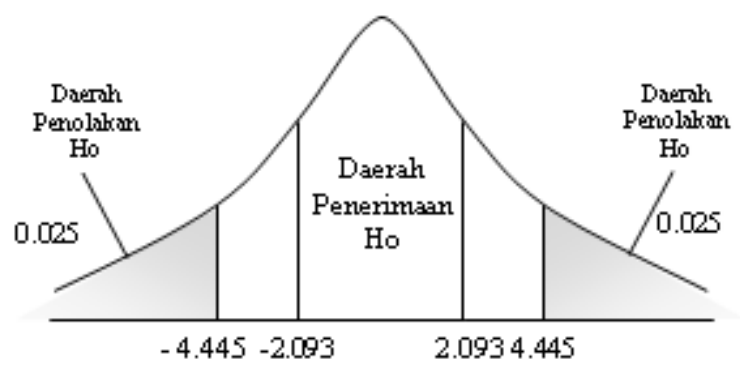

\section{Koefisien Determinasi (Kd)}


Adalah persentase pengaruh. Didapat persentase pengaruh variabel pola pelatih kooperatif terhadap motivasi berprestasi sebesar $50.98 \%$.

\section{PEMBAHASAN}

Penelitian pola pelatih kooperatif dan motivasi berprestasi ini dengan menggunakan one shot model menghasilkan pengaruh positif yang signifikan. Data ini menggunakan atlet bola basket putri SMA 17 Agustus 1945 Surabaya sejumlah 15 orang sebagai subjek penelitian. Data yang diperoleh dari hasil perhitungan jika $t_{\text {hitung }}>t_{\text {tabel }}$ maka $\mathrm{Ha}$ diterima (ada pengaruh), thitung yang didapat adalah 0.714 dan $t_{\text {tabel }} 0.433$ sehingga $t_{\text {hitung }}$ $>t_{\text {tabel }}$ pada sig. $5 \%$ sehingga menunjukkan ada pengaruh variabel pola pelatih kooperatif terhadap motivasi berprestasi siswa dan persentase menunjukkan $50.98 \%$ pengaruh pola pelatih kooperatif terhadap motivasi berprestasi.

Motivasi untuk melakukan aktivitas atau perilaku ini bisa datang dari diri sendiri (motivasi intrinsik) dan dari lingkungan sekitar (motivasi ekstrinsik). Motivasi intrinsik dibidang olahraga sangat membantu atlet untuk mendorong dirinya dalam menggeluti olahraga yang digemarinya. Komarudin (2013:27) mendefinisikan bahwa motivasi ekstrinsik adalah motivasi yang timbul karena adanya faktor luar yang mempengaruhi dirinya. Dan motivasi berprestasilah yang harus dimiliki oleh seorang olahragawan sebagai penghargaan dari hasil kerja keras latihan. Motivasi prestasi adalah sebuah dorongan untuk sebuah keunggulan baik individu, tim, mengungguli orang lain, atau kesempurnaan dalam melaksanakan sebuah misi prestasi.

Dalam ruang lingkup olahraga, pelatih adalah orang yang sangat dekat dengan atlet. Sehingga tidak menutup kemungkinan bahwa kedekatan pelatih dan atlet akan berpengaruh besar terhadap keinginan berlatih, memenangkan pertandingan, dan memperbaiki penampilan atau performa. Melalui gaya (style) yang kooperatif sebagai sebuah ciri khas dari se- 
orang pelatih akan membantu meningkatkan motivasi untuk berprestasi, sehingga pelatih dapat merealisasikan program yang telah disusunnya.

Penelitian tentang pola pelatih ini merupakan penelitian baru dan tentunya masih terdapat banyak kelemahan, baik dari sumber, subjek penelitian, maupun indikator-indikator dari variabel pola pelatih dan motivasi berprestasi.

\section{KESIMPULAN}

Berdasarkan hasil penelitian, analisis data didapat kesimpulan bahwa:

1. Adanya pengaruh dari pola pelatih kooperatif terhadap motivasi berprestasi atlet bola basket putri SMA 17 Agustus 1945 Surabaya. Koefisien korelasi yang menghasilkan nilai sebesar 0.714 , masuk dalam kategori kuat. Kemudian uji signifikan menunjukkan jika $t_{\text {hitung }}>$ $t_{\text {tabel }}$ yaitu $4.445>2.093$, sehingga dinyatakan signifikan.

2. Hasil perhitungan $\mathrm{r}_{\text {hitung }}$ (koefisien korelasi) dibandingkan dengan $r_{\text {tabel }}$ menunjukkan bahwa $r_{\text {hitung }}>r_{\text {tabel }}$ yaitu $0.714>0.433$ sehingga pada ketentuannya bila $\mathrm{r}_{\text {hitung }}>\mathrm{r}_{\text {tabel}}, \mathbf{H}_{\mathbf{a}}$ diterima. $\mathrm{H}_{\mathrm{a}}$ diterima menunjukkan bahwa terdapat pengaruh pola pelatih kooperatif terhadap motivasi berprestasi atlet bola basket putri SMA 17 Agustus 1945 Surabaya.

3. Motivasi berprestasi atlet bola basket putri SMA 17 Agustus 1945 Surabaya dipengaruhi oleh pola pelatih kooperatif sebesar $\mathbf{5 0 . 9 8 \%}$ dan $49.02 \%$ sisanya ditentukan oleh faktor lainnya.

4. Ada pengaruh signifikan yang positif sebesar $50.98 \%$ pola pelatih kooperatif terhadap motivasi berprestasi atlet bola basket putri SMA 17 Agustus 1945 Surabaya.

\section{SARAN}

Dari penelitian yang telah dilakukan ini, peneliti berharap ada penelitian selanjutnya dengan kelompok umur dan cabang olahraga yang berbeda sehingga penelitian bisa lebih luas dan lebih baik lagi. Atau juga dapat melakukan penelitian dengan 
pola pelatih yang berbeda (selain pola pelatih kooperatif). Dapat pula menambah pertanyaan-pertanyaan dari skala yang bersangkutan sehingga validitas dan reliabilitas semakin tinggi nilainya. Alangkah baiknya jika penelitian dilakukan dengan tidak mengganggu program latihan pelatih, termasuk juga jika melakukan observasi maupun wawancara kepada atlet maupun pelatih yang bersangkutan.

\section{DAFTAR PUSTAKA}

Arikunto, Suharsimi. (2010). Prosedur penelitian: suatu pendekatan praktik. Jakarta: Rineka Cipta.

- (2012). Dasar-dasar evaluasi pendidikan. Jakarta: Bumi Aksara.
Gordon, Dan. (2009). Coaching science. Inggris: Learning Matters Ltd.

Hamalik, Oemar. (2010). Psikologi belajar dan mengajar. Bandung: Sinar Baru Algesindo.

Komarudin. (2013). Psikologi olahraga: latihan mental dalam olahraga kompetitif. Bandung: Rosda.

Martens, Rainer. (2004). Third edition: succesful coaching. USA: Human Kinetics.

Sugiyono. (2005). Statistika untuk penelitian. Bandung: Alfabeta.

Sujarweni, V.W. (2015). SPSS untuk penelitian. Yogyakarta: Pustaka Baru Press.

Sukadiyanto. (2011). Pengantar teori dan metodologi melatih fisik. Bandung: Lubuk Agung. 